\title{
ON THE NEWTONIAN THERMAL ANALYSIS OF CASTING: A CRITICAL APROACH.
}

\section{Kadir Can ERBAŞ (kcerbas@gmail.com)}

TED Universty Basic Sciences Unit, Ankara, Turkey

\begin{abstract}
One of the primary aims of Newtonian thermal analysis (NTA) is the prediction of latent heat and finding solid fraction. When the prediction is made, Newtonian baseline (NBL) is computed, and the difference to experimental cooling rate curve is analyzed.

In this study, it was seen that NBL calculations had some contradictions and that latent heat calculations gave high errors. After determining these contradictions, a new method, called one-capacitive-system baseline (OCSBL), was developed by gathering the solution advises to each other. Cooling curve of mold-insulated pure Tin was analyzed by both methods to test them. It was seen that OCSBL predicted the latent heat better than NBL when the results were compared with the literal values.
\end{abstract}

Keywords: Newtonian thermal analysis, solid fraction, latent heat 


\section{METAL DÖKÜMLERININ NEWTON SALISI ANALIZİ ÜZERINE: ELEŞTİREL BİR YAKLAŞIM}

Kadir Can ERBAŞ (kcerbas@gmail.com)

TED Üniversitesi Temel Bilimler Bölümü, Ankara, Türkiye

\section{ÖZET}

Döküm için Newtonsal 1S1 analizinin başlıca amaçları arasında ergime 1Sısı tahmini ve katı kesrinin bulunması gelmektedir. Bu tahmin yapılırken Newton taban eğrisi (NTE) hesaplanıp deneysel soğuma eğrisi arasındaki fark analiz edilmektedir.

$\mathrm{Bu}$ çalışmada, Newton taban eğrisi hesaplamanın bazı çelişkileri barındırdığı ve ergime 1sısı hesaplarının yüksek hatalar verdiği görüldü. Bu çelişkiler tespit edildikten sonra, her birine getirilen çözüm önerileri derlenerek, tekli-kapasitifsistem taban eğrisi (TKSTE) adında yeni bir yöntem geliştirildi. İki yöntemi test etmek için, kaptan yalıtılmış saf kalayın soğuma eğrisi iki yöntemle de analiz edildi. Sonuçlar literatürdeki termal değerler ile kıyaslandığında, TKSTE nin NTE den daha iyi ergime 1sısı tahmin ettiği görüldü.

Anahtar Kelimeler: Termal Analiz, Ergime Islsl, Katı Kesri 


\section{INTRODUCTION}

Newtonian thermal analysis (NTA) for casting aims to compute latent heat and solid fraction evolution of a solidifying metal by analyzing cooling data. For this purpose, a hot melt is poured into a mold, and temperature is recorded by a thermocouple at every second while the sample is cooling and solidifying [1]. One of the techniques that has been frequently used is computer aided cooling curve analysis (CA-CCA). It requires complicated mathematical tools and sophisticated computer software to analyze the temperature data [2]. The main equation for defining thermal characteristics of the sample is Newton's Law of Cooling (NLC). NLC simply states that the rate of heat loss is proportional to the temperature difference between the sample and ambient.

$$
\frac{d Q_{\text {loss }}}{d t}=-h A\left(T-T_{a}\right)
$$

where dQloss/dt is the rate of heat loss of the sample, A is effective surface area of the sample, $\mathrm{h}$ is heat transfer coefficient between the hot sample and ambient, and Ta is the ambient temperature [3]. NLC (1) describes simple cooling without any source terms that may be caused by thermal reactions such as phase transformation. However, the main point in NTA procedure is to analyze solidification. Therefore, mathematical description of the phase transformational heat rate must be included to the equation. For this purpose, solid fraction is used to represent this source term by the help of latent heat. The rate of heat in a solidification process is given by

$$
\frac{d Q_{L}}{d t}=m L_{f} \frac{d f_{s}}{d t}
$$

where QL is the heat arising from latent heat release, $m$ is the mass of sample, Lf is latent heat of fusion, and fs is solid fraction [4]. As a result, Equation 1 and 2 may be combined in the definition of net heat rate of the sample.

$$
\frac{d Q_{n e t}}{d t}=\frac{d Q_{\text {loss }}}{d t}+\frac{d Q_{L}}{d t}
$$

By the definition of net heat change in terms of specific heat, Equations 1, 2 , and 3 yield 


$$
\begin{aligned}
& m c_{p} \frac{d T}{d t}=-h A\left(T-T_{a}\right)+m L_{f} \frac{d f_{s}}{d t} \\
& \frac{d T}{d t}=-\frac{h A}{m c_{p}}\left(T-T_{a}\right)+\frac{L_{f}}{c_{p}} \frac{d f_{s}}{d t}
\end{aligned}
$$

where $\mathrm{cp}$ is the specific heat of the sample.

Equation 5 roughly explains a typical cooling process of a solidifying metal from pouring temperature to cold solid phase. From the temperature data recorded in the NTA experiment, the coefficients of the equation are computed by the curve fitting for zero curve (or baseline). Baseline is the hypothetical curve under the assumption of no-phase transformation [5]. In the case of no-phase transformation, Equation 1 is assumed valid, and the solution for cooling rate as a function of time defines a zero curve. This solution, which is in the form of exponential decay, is given by

$$
\left(\frac{d T}{d t}\right)_{N B L}=a e^{-b t}
$$

where $\mathrm{a}$ and $\mathrm{b}$ are the parameters that may be calculated experimentally, and the subscript denotes Newtonian baseline (zero curve). They are defined as:

$$
b=\frac{h A}{m c_{p}}, \quad a=-\left(T_{0}-T_{a}\right) \frac{h A}{m c_{p}}
$$

Newtonian baseline (NBL), in Equation 6, has exponential form so its coefficient can be computed by curve fitting tools of any mathematical software by excluding the solidification region of dT/dt curve. After obtaining the coefficients, latent heat and solid fraction are computed by the difference between NBL and the experimental cooling curve. Since the values of solid fraction at the start and end times of solidification (ts and te) are zero and unity respectively, this difference can be found by integrating both sides between ts and te.

$$
L_{f}=c_{p} \int_{t_{s}}^{t_{e}}\left[\left(\frac{d T}{d t}\right)_{\exp }-\left(\frac{d T}{d t}\right)_{N B L}\right] d t
$$




$$
f_{s}=\frac{c_{p}}{L_{f}} \int_{t_{s}}^{t}\left[\left(\frac{d T}{d t}\right)_{\exp }-\left(\frac{d T}{d t}\right)_{N B L}\right] d t
$$

where ts and te are the start and end times of solidification [6]. Graphical expression of Equations 8 and 9 are shown in Figure 1. Latent heat per specific heat $(\mathrm{Lf} / \mathrm{cp})$ is the area between two curves in the interval $t s<t<t e$ while $\mathrm{fs}$ is the cumulative area between ts and $\mathrm{t}$.

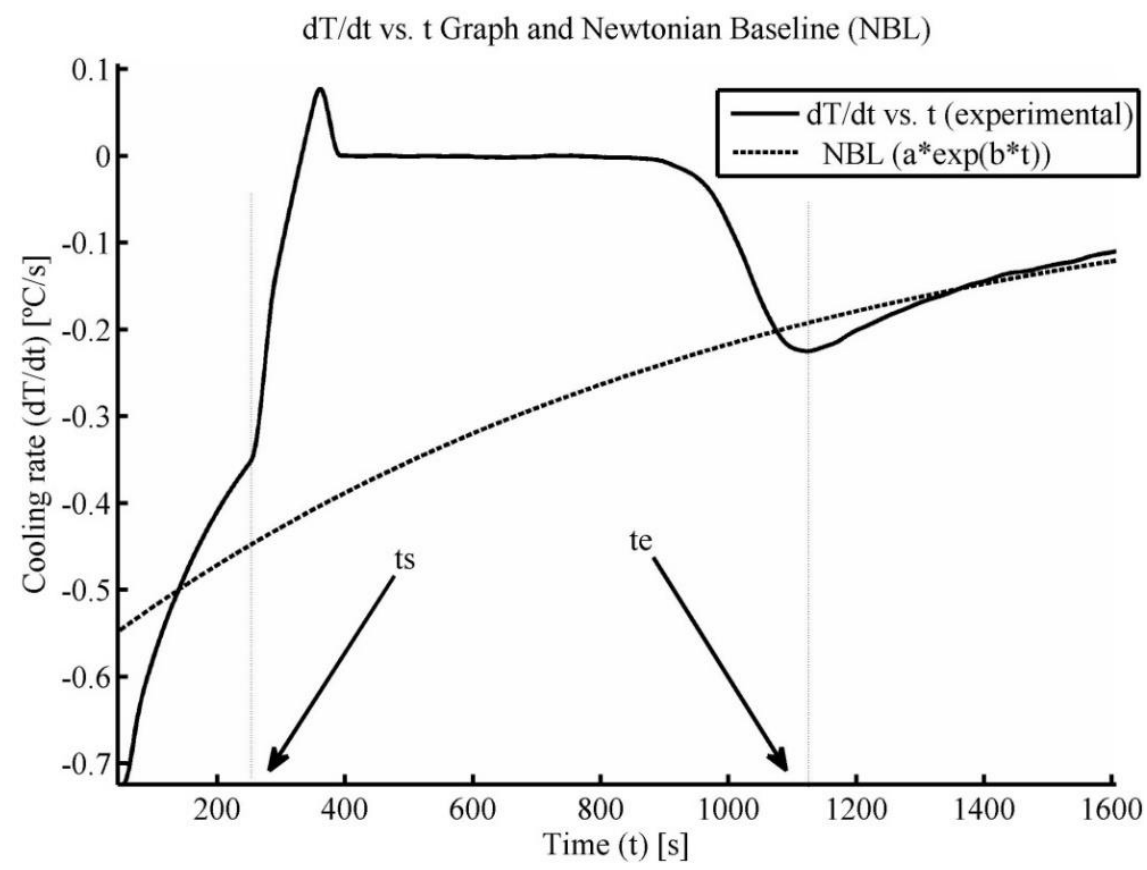

Figure 1. Cooling rate curve and Newtonian baseline (NBL). Start and end time of solidifications are denoted by ts and te respectively.

\section{EVALUATION OF NTA}

Newtonian zero curve method has some theoretical contradictions and limitations. It does not consider the thermal capacity of the mold, and therefore, the temperature of mold. It could be neglected if the mold's capacity were very smaller than metal's capacity. Emadi et.al. reported that they used a crucible whose thermal mass was less than $0.5 \%$ of the total thermal mass of the system [7]. Yet, the thermal capacity of resin-coated sand molds used in this study were measured $117 \mathrm{~J} / \mathrm{K}$, while that of pure 
tin is $83 \mathrm{~J} / \mathrm{K}$. Therefore, it is voluntary to eliminate the effects of thermal capacity of the mold in the experiments.

The lack of standards on the choice of temperature interval and curve fitting methodology is another restriction of NTA. Different choice of the temperature intervals around solidification affects the outputs of curve fitting, and certainly, the results of latent heats. It is observed that different trials of latent heat calculations by several data inclusions gave inconsistent results. Narrower intervals may be somewhat reliable, but they did not work at every attempt [1].

Moreover, NBL requires data smoothing in case time derivative of cooling curve could be plotted. Whereas, smoothing of the temperature data and its limits are variable for the choice of researchers. More smoothed data results in a smooth but deviated derivative. It deforms the original data, so it gives incidental outputs at every different trial of smooth parameters.

NBL uses exponential decay as a choice of zero-curve. Equation 6 is tried to fit the cooling rate curve in the non-solidification part. However, the integration constant "a" in (6) should be particular to solid and liquid region because it comes from the initial conditions of (5). In fact, the correct solution of the differential equation in (5) should be (10) or (11).

$$
\begin{aligned}
& \left(\frac{d T}{d t}\right)_{z c}=\left(a_{S} \theta\left(t-t_{e}\right)+a_{L} \theta\left(t_{s}-t\right)\right) e^{-b t} \\
& \left(\frac{d T}{d t}\right)_{z c}= \begin{cases}a_{S} e^{-b t} & \text { solid phase } \\
a_{L} e^{-b t} & \text { liquid phase }\end{cases}
\end{aligned}
$$

where $\mathrm{aS}$ and $\mathrm{aL}$ are the integration constants for solid and liquid phases, $\theta$ is Heaviside step function, and zc denotes zero curve (or baseline). Alternatively, this contradiction can be expressed graphically. In figure 2, experimental dT/dt graph and expected no-solidification theoretical curve are shown. If there were no solidification, the cooling rate curve would continue on a different path in the solid region. 


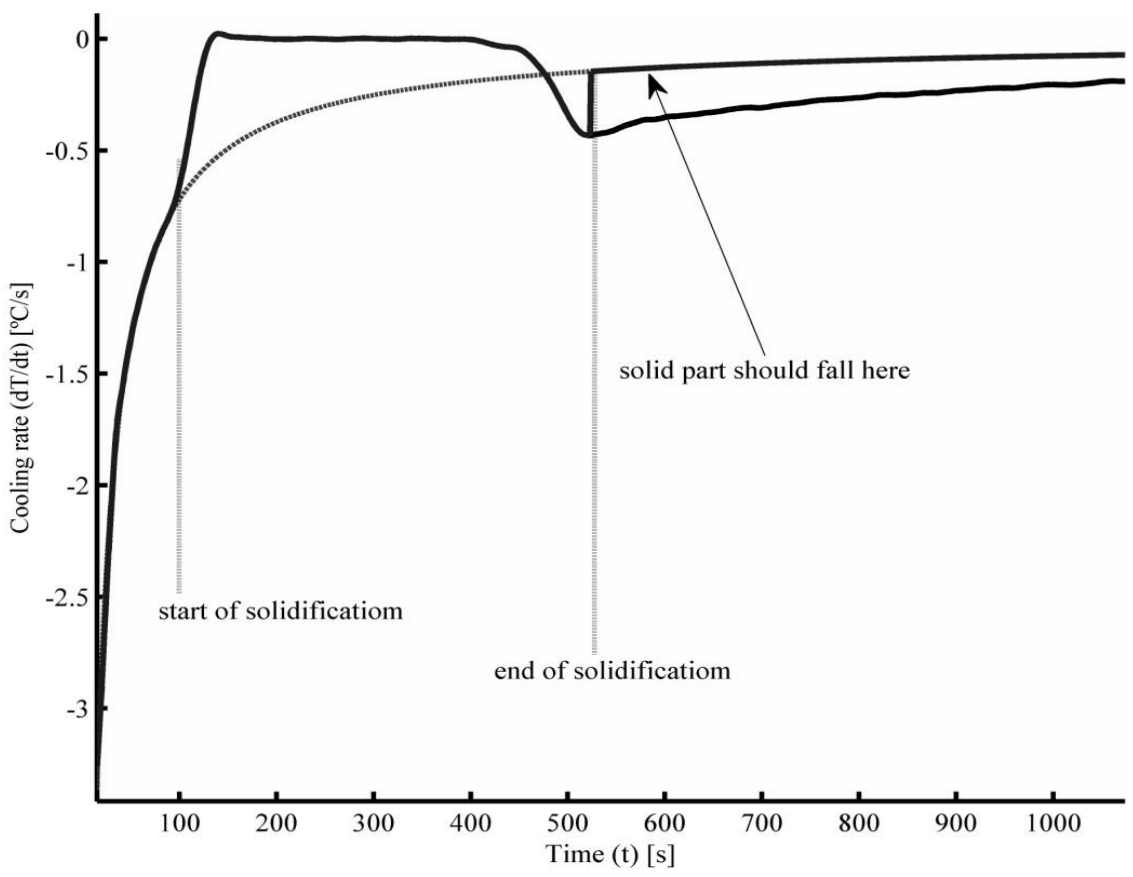

Figure 2. Cooling rate (dT/dt) with respect to time and the virtual curve if solidification did not occur.

Another restriction of NBL may be the lack of radiative terms or other temperature dependent effects. Cooling with radiation requires nonlinear temperature terms in Equation 5, and therefore, zero curve definition [8]. Temperature dependent heat transfer coefficients and/or specific heat are other effects having contributions to zero curves $[9,10]$.

- In summary, the critics of NTA may be listed as follows:

- Effects of thermal capacity of the mold should be eliminated.

- Temperature interval or other variations in the analysis should be standardized.

- Smoothing, therefore differentiating the cooling curve, should be avoided

- Different initial conditions, which are special to solid and liquid phases, should be taken into account.

- Cooling with radiation or other temperature dependent effects such as varying specific heat should be studied. 
All of the critics above were considered to propose an alternative model to NTA. This model is named One-capacitive-system baseline (OCSBL) and explained in the next chapter. This model may be applied to small-thermalmass-crucible experiments or the experiments with thermal insulation between the metal and mold to eliminate mold's effects.

\section{ONE-CAPACITIVE-SYSTEM BASELINE}

Considering very complicated nonlinear temperature contributions to the differential equation, one can start with to write the cooling rate as a function of temperature (Equation 12). Function $\mathrm{F}$ represents the contributions from radiation and other temperature-dependent-parameter effects. Then, Equation 5 becomes:

$$
\frac{d T}{d t}=F(T)+\frac{L_{f}}{c_{p}} \frac{d f_{s}}{d t} \theta_{P T}(t)
$$

$\theta \mathrm{PT}(\mathrm{t})$ defines the validation interval of solid fraction. It is given by

$$
\theta_{P T}(t)=\left\{\begin{array}{lc}
1 & t_{s}<t<t_{e} \\
0 & \text { otherwise }
\end{array}\right.
$$

This intricate function $\mathrm{F}$ can be represented by the first degree Taylor polynomial about melting temperature. Equation 12 can be redefined with new coefficients $b$ and $c$ different from their original meaning: heat transfer coefficients and ambient temperature.

$$
\frac{d T}{d t}=-b(T-c)+\frac{L_{f}}{c_{p}} \frac{d f_{s}}{d t} \theta_{P T}(t)
$$

From now on, one should not expect that the parameters $b$ and c correspond to thermal coefficients and the ambient temperature. Equation 14 is a first order linear differential equation and solved by the help of integration factor [11]. The solution is summarized in Equations 15-18.

$$
\left[\frac{d T}{d t}+b\left(T-T_{a}\right)\right] e^{b t}=e^{b t} \frac{L_{f}}{c_{p}} \frac{d f_{s}}{d t} \theta_{P T}(t)
$$




$$
\begin{aligned}
& \frac{d}{d t}\left[e^{b t}\left(T-T_{a}\right)\right]=e^{b t} \frac{L_{f}}{c_{p}} \frac{d f_{s}}{d t} \theta_{P T}(t) \\
& e^{b t}\left(T-T_{a}\right)-\left(T_{0}-T_{a}\right)=\int_{0}^{t} e^{b t} \frac{L_{f}}{c_{p}} \frac{d f_{s}}{d t} \theta_{P T}(t) d t \\
& T=T_{a}+\left[T_{0}-T_{a}+\int_{0}^{t} e^{b t} \frac{L_{f}}{c_{p}} \frac{d f_{s}}{d t} \theta_{P T}(t) d t\right] e^{-b t}
\end{aligned}
$$

Since $\theta \mathrm{PT}(\mathrm{t})$ is zero in the single phase interval, the integral in Equation 18 gives different constants ( $\mathrm{aS}$ and $\mathrm{aL})$ for the expression of single phase temperature (TSP).

$$
T_{S P}=\left(a_{S} \theta\left(t-t_{e}\right)+a_{L} \theta\left(t_{s}-t\right)\right) e^{-b t}+c
$$

This single phase definition of temperature can be fitted to experimental temperature data in the no-solidification interval ( $t<t$ s and $t>t e)$. Curve fitting outputs give the required parameters $\mathrm{b}$ and $\mathrm{c}$, and a new zero curve, called One-Capacitive-System Baseline (OCSBL), is defined by the help of Equation 14 as follows:

$$
\left(\frac{d T}{d t}\right)_{O C S B L}=-b\left(T_{\exp }-c\right)
$$

where Texp is the experimental data recorded from the temperature measurement. The rest of the procedure is the same with Equations 8 and 9.

Main points for this analysis is to select a narrow temperature interval around melting point and to set ambient temperature, represented by c, free because the first order Taylor series approximation requires a narrow region. Terms in Taylor series distort the parameters from their intended meanings. That is, the parameter $\mathrm{c}$ may be computed by curve fitting tool different from the ambient temperature.

\section{THE EXPERIMENT}

This new baseline was tried on an experiment that was made by pure Tin in an insulated mold. The temperature range $50 \mathrm{oC}$ below or above melting temperature was selected as analysis interval. When Equation 19 was tried 
to fit temperature data in the interval, the outputs were obtained as in Figure 2 and Table 1.

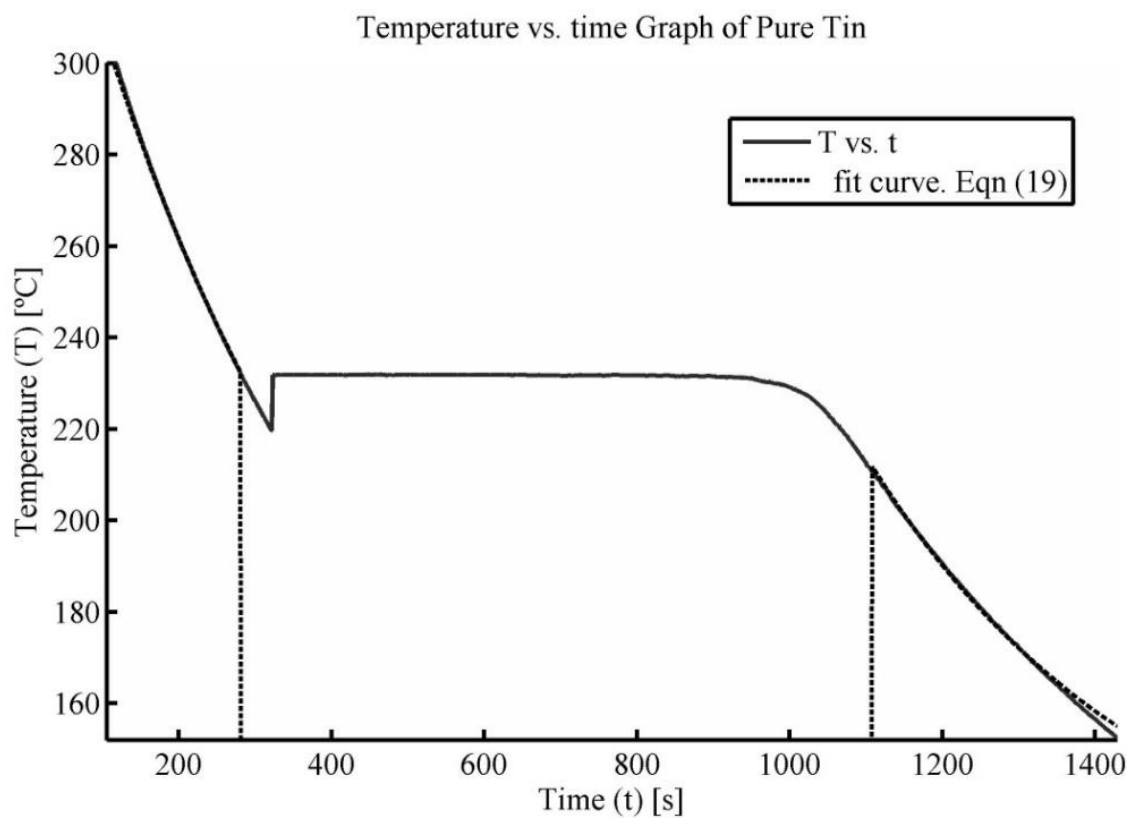

Figure 3.Temperature vs. time graph and OCSBL.

Table 1. Output of curve fitting tool of MATLAB R2010a.

\begin{tabular}{|c|c|}
\hline General model & Goodness of fit \\
\hline \multicolumn{2}{|c|}{$\begin{aligned} T(t)= & (a s * \exp (-b * t)+c) * \text { heaviside }(t-1107) \\
& +(a l * \exp (-b * t)+c) * \text { heaviside }(282-t)\end{aligned}$} \\
\hline $\begin{array}{l}\text { Coefficients (with 95\% confidence bounds): } \\
\begin{aligned} \text { al } & =253.7(253.3,254.2) \\
\text { as } & =2010(1963,2056) \\
\text { b } & =0.002733(0.002705,0.002761) \\
c & =114.5(113.7,115.3)\end{aligned}\end{array}$ & $\begin{array}{ll}\text { SSE } & : 56.02 \\
R \text {-square } & : 0.9999 \\
\text { Adjusted R-square } & : 0.9999 \\
\text { RMSE } & : 0.3886\end{array}$ \\
\hline
\end{tabular}

\section{RESULTS AND DISCUSSION}

After obtaining the parameters $\mathrm{b}$ and $\mathrm{c}$ from Table 1, it was put in Equation 20 to get zero curve. Latent heat per specific heat and solid fraction were calculated by Equation 8 and 9. Latent heat per specific heat value (Lf/cp) for pure Tin (Sn) was calculated $240 \mathrm{~K}$ by OCSBL. Solid fraction evolution in time is shown in Figure 4. 


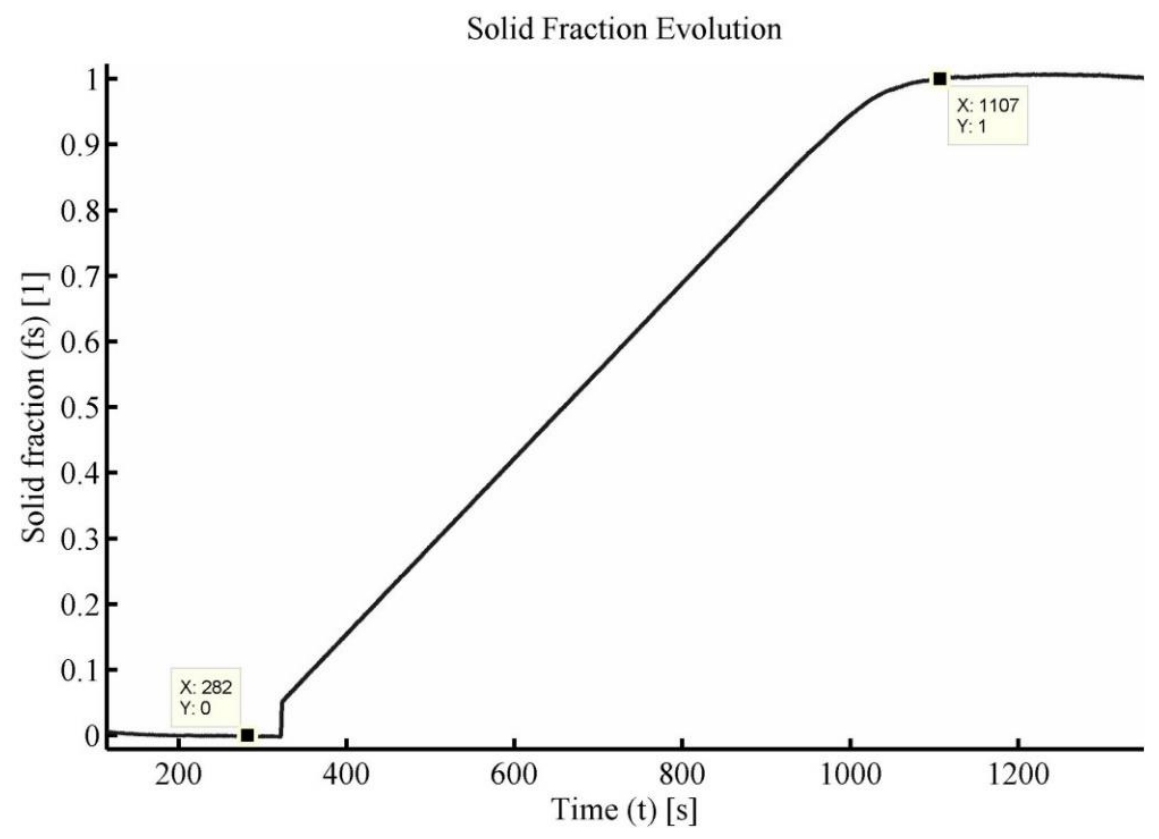

Figure 4. Solid fraction for pure Sn calculated by OCSBL.

For comparison, the literal values of latent heat of pure Sn and the value calculated by NBL were also found. Result of NBL was made by the zero curve method explained in the first Chapter. The literal value was found by Perry's Chemical Engineering Handbook [12]. These data is listed in Table 2.

\begin{tabular}{|l|l|l|l|}
\hline & OCSBL & NBL & LITERAL \\
\hline \hline Specific heat (solid phase) [cal.mol-1.K-1] & - & - & 7.24 \\
\hline Specific heat (liquid phase) [cal.mol-1.K-1] & - & - & 6.60 \\
\hline Specific heat (average) [cal.mol-1.K-1] & - & - & 6.92 \\
\hline Latent heat [cal.mol-1] & - & - & 1720 \\
\hline Latent heat per specific heat [K] & 240 & 217 & 249 \\
\hline
\end{tabular}

Table 2: Thermal properties of pure Sn. Average specific heat was calculated by averaging solid and liquid phase values at melting temperature $(504 \mathrm{~K})$. This average value was used in literal latent heat per specific heat. 
As seen in Table 2, OCSBL predicted better result than NBL for the estimation of latent heat. Literal average of $\mathrm{Lf} / \mathrm{cp}$ value is calculated 240 K about melting point. NBL and OCSBL computed this value 217 and 240 respectively. Their percentage errors are $-13 \%$ and $-3.6 \%$ respectively. The temperature ranges of both methods were set to 50 degrees above and below melting point. Changing the range yielded different outputs. For example, NBL and OCSBL gave 229 and $250 \mathrm{~K}$ when the range was taken 100 degrees above and below melting point.

One of the advantages of OCSBL is that it does not need deriving temperature data. Differentiating temperature with respect to time requires no standardized choices for the sake of smoothing. More smoothed data does not represent original experiment. Therefore, it should be discussed whether smoothing is ethical or not. Since there is no need to derivative, smoothing is not used in OCSBL.

\section{CONCLUSION}

NTA for casting was evaluated from different perspectives. After the evaluation, the suggested method, OCSBL, was seen a better predictor for latent heat than NBL.

It was seen that the primary restriction of NBL was not to include different initial conditions for solid and liquid phases. Since the definition of the baseline, in fundamental, is based on no phase transformation case, it can not be represented by single phase region that omits solidification region. Solidification intervenes between solid and liquid phases, therefore initial condition is jumped to a new outset. This failure of NBL is corrected by choosing different integration constants for each phase in the mathematical representation of baseline.

Another failure of NBL originates from taking derivative of temperature with respect to time. Because of noisy temperature data, NBL has to make smoothing. However, smoothing deforms the original data, and deviates the derived curve from its original values. In the new model, there is no need to derivative and smoothing. OCSBL uses the cooling curve itself for analysis. 
Determination of temperature range for thermal analysis was detected another restriction. There are no standards for choosing proper temperature interval. Different choices of ranges produce different latent heat results. The range should be so small that differential equation can be explained by the first degree polynomial, but so wide that curve fitting can take enough information about temperature data. In this study, $100 \mathrm{oC}$ above and below melting temperature arose an advisable temperature range.

\section{REFERENCES}

[1] K. C. Erbaş. Suggestion of a new model for Newtonian thermal analysis of solidification. PhD Thesis, METU (2013), pp. 49-71.

[2] U. Ekpoom and R. W. Heine. Thermal analysis by differential heat analysis (DHA) of cast iron. AFS Trans., Vol. 85, (1981), pp. 27-38

[3] C. O'Sullivan. A simple experiment to study cooling by convection and radiation. Department of Physics, National University of Ireland Cork, (2006).

[4] P. Marchwica, J.H. Sokolowski and W.T. Kierkus. Fraction solid evolution characteristics of $\mathrm{AlSiCu}$ alloys - dynamic baseline approach. Journal of Achievements in Materials and Manufacturing Engineering. Vol. 47, (2011), p.116

[5] A. Çetin. Assessment and modelling of particle clustering in cast aluminum matrix composites. PhD Thesis, METU (2008), pp. 13-19

[6] L. S. Chao and W. C. Wu. Macro-micro modeling of solidification. Proc. Natl. Counc. ROC (A), Vol. 23, (1999), pp. 622-629

[7] D. Emadi, V. Whiting, M. Djurdjevic, Witold T. Kierkus and J. Sokolowski. Comparison of newtonian and fourier thermal analysis techniques for calculation of latent heat and solid fraction of aluminum alloys. Association of metallurgical engineers serbia and montenegro scientific paper. (2004), pp. 91-106.

[8] L. A. Dombrovsky and T.N. Dinh. The effect of thermal radiation on the solidification dynamics of metal oxide melt droplets. Nuclear Engineering and Design 238, (2008), pp. 1421-1429.

[9] F. Lau, W.B. Lee, S.M. Xiong and B.C. Liu. A study of the interfacial 
heat transfer between an iron casting and a metallic mould. Journal of Materials Processing Technology 79, (1998), pp. 25-29.

[10] J. N. Silva, D. J. Moutinhoa, A. L. Moreirab, I.L. Ferreirac and O.L. Rochaa. Determination of heat transfer coefficients at metal-mold interface during horizontal unsteady-state directional solidification of $\mathrm{Sn}-\mathrm{Pb}$ alloys. Materials Chemistry and Physics, 130, (2011), pp. 179185 .

[11] W. E. Boyce and R.C. Diprima. Elementary Differential Equations and Boundary Value Problems. 7th ed., Wiley, New York, (2001)

[12] R. H. Perry, and D. W. Green. Perry's Chemical Engineers' Handbook. 7th ed. McGrawHill, New York (1999), section 2. 